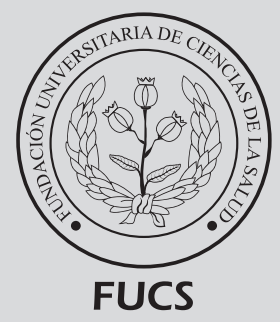

\title{
COVID-19 en Colombia: un año después de confirmar su primer caso
}

\section{COVID-19 in Colombia: one year since the first case was confirmed}

${ }^{a}$ Ingeniero. Magister en Gestión de la Tecnología Educativa, Especialista en Administración de la Informática Educativa.

Docente de matemáticas e Investigador, Secretaría de Educación de Soacha, Cundinamarca.

\section{R E S U M E N}

Introducción: : la enfermedad por coronavirus 2019 (COVID-19) es una enfermedad respiratoria aguda infecciosa producida por un nuevo coronavirus. La Organización Mundial de la Salud (OMS) fue conocedora de casos de neumonía de etiología microbiana desconocida asociados con la ciudad de Wuhan, provincia de Hubei, China, el 31 de diciembre de 2019. Objetivo: presentar la tendencia de la enfermedad COVID-19, un año después de registrarse el primer caso de contagio en Colombia. Metodología: el trabajo de investigación se realizó mediante un enfoque cuantitativo. Resultados: se calcularon las tasas de letalidad por COVID-19 por meses en Colombia, se apreció que el mes con mayor porcentaje de letalidad por cada 100 habitantes está en primer lugar abril 2020 con una tasa de 4,71\%, y febrero 2021 con 3,68\%. Para el caso de la incidencia se determinó que el mes con mayor tasa de porcentaje se ubicó en el mes de enero 2021 con 0,884\% y diciembre 2020 con 0,664\%. En la otra medida epidemiológica de la prevalencia, se fijó que los meses con mayor tasa de porcentaje se ubicó en 2021: enero 4,1\%, y febrero con un 4,41\%. Conclusión: la letalidad, la incidencia y prevalencia de la enfermedad COVID-19 en Colombia ha tenido una serie de fluctuaciones durante su primer registro de contagio en nuestro país, ahora, con el inicio de la vacunación se genera un espacio para disminuir las tasas de contagio y letalidad.

Palabras clave: COVID-19, SARS-CoV-2, pandemia, letalidad, incidencia, prevalencia.

(C) 2021 Fundación Universitaria de Ciencias de la Salud - FUCS. Este es un artículo Open Access bajo la licencia CC BY-NC-ND (http://creativecommons.org/licenses/by-nc-nd/4.0/).

\section{INFORMACIÓN DEL ARTÍCULO}

Historia del artículo:

Fecha recibido: marzo 2 de 2021

Fecha aceptado: marzo 19 de 2021

\footnotetext{
Autor para correspondencia.

Jorge Enrique Díaz Pinzón jediazp@unal.edu.co
}

DOI

10.31260/RepertMedCir.01217372.1182 


\section{A BS T R ACT}

Introduction: coronavirus disease 2019 (COVID-19) is an acute respiratory infectious disease caused by a novel coronavirus. The World Health Organization (WHO) was aware of cases of pneumonia of unknown microbial etiology associated with the city of Wuhan, province of Hubei, China, on December 31 2019. Objective: to present the trend of COVID-19 disease one year after the first positive case was registered in Colombia. Methodology: this research work was carried out using a quantitative approach. Results: the monthly lethality rates for COVID-19 in Colombia were estimated. The highest lethality rate per 100 inhabitants occurred in April 2020 4.71\%, in the first place, and in February 2021 3.68\%. The highest incidence was reported in the months of January $20210.884 \%$ and December $20200.664 \%$. The highest prevalence, the other epidemiological measure, was reported in early 2021 in the months of: January 4.1\%, and February 4.41\%. Conclusion: COVID-19 disease lethality, incidence and prevalence in Colombia have had a series of fluctuations since the first case was confirmed in our country. Now, as vaccination has begun, it offers the possibility of reducing contagion and mortality.

Key words: COVID-19, SARS-CoV-2, pandemic, lethality, incidence, prevalence.

(C) 2021 Fundación Universitaria de Ciencias de la Salud - FUCS. This is an open access article under the CC BY-NC-ND license (http://creativecommons.org/licenses/by-nc-nd/4.0/).

\section{INTRODUCCIÓN}

La enfermedad por coronavirus 2019 (COVID-19) es una enfermedad respiratoria aguda infecciosa producida por un nuevo coronavirus. La Organización Mundial de la Salud (OMS) fue conocedora de casos de neumonía de etiología microbiana desconocida asociados con la ciudad de Wuhan, provincia de Hubei, China, el 31 de diciembre 2019.

La OMS informó más tarde que se había manifestado un nuevo coronavirus en muestras tomadas de estos pacientes. Desde entonces, la epidemia se ha acrecentado y se ha extendido velozmente por todo el mundo, y la OMS primero declaró una emergencia de salud pública de jerarquía internacional el 30 de enero 2020 y luego la declaró formalmente como pandemia el 11 de marzo $2020{ }^{1}$

El síndrome respiratorio agudo severo (SARS), el síndrome respiratorio de Oriente Medio (MERS) y el COVID-19 detonaron en las últimas décadas y son causados por cambiantes cepas de coronavirus (CoV). Se piensa que estos virus se originan en los murciélagos y se han transmitido a los humanos a través de huéspedes intermediarios. ${ }^{2}$

Nuestro conocimiento actual de COVID-19 proviene en gran parte de la vigilancia de enfermedades y los estudios epidemiológicos realizados durante las primeras fases de la pandemia en China. ${ }^{3-5}$ La vigilancia y el rastreo de contactos son componentes críticos de una respuesta de salud pública eficaz al COVID-19. ${ }^{6,7}$ Los esfuerzos médicos y de salud pública actuales se concentran en el uso de medidas de salud pública basadas en pruebas para aplacar la propagación del virus, atizar el desarrollo de vacunas y mejorar la terapéutica y otras intervenciones médicas para ayudar a las personas infectadas. ${ }^{8}$ Se han reconocido casos en todos los continentes y el 6 de marzo se confirmó el primero en Colombia. La infección se evidencia cuando una persona enferma tose o estornuda y expulsa partículas del virus que entran en contacto con otras personas. ${ }^{9}$

\section{Tasa de letalidad}

La letalidad es una medida de la gravedad de una enfermedad estimada desde el punto de vista poblacional y se precisa como la proporción de casos de una enfermedad que surgen mortales con respecto al total de casos en un periodo determinado. La medida muestra la relevancia de la enfermedad en términos de su disposición para producir la muerte y se deduce de la siguiente manera. ${ }^{10,11}$

\section{Número de muertes por una enfermedad

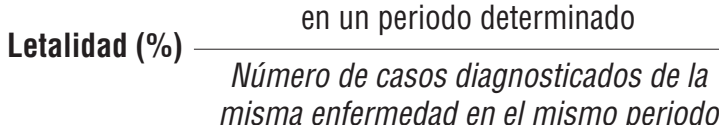

(x 100)

La letalidad en sentido exacto, es una proporción ya que enuncia el número de defunciones entre el número de casos del cual las defunciones forman parte. Sin embargo, universalmente se expresa como tasa de letalidad y se registra como el porcentaje de muertes de una causa específica con respecto al total de enfermos por esa causa. ${ }^{10,11}$

\section{Incidencia (I)}

Se define como el número de casos nuevos de una enfermedad que se desarrollan en una población durante un período de tiempo determinado. ${ }^{12} \mathrm{Su}$ cálculo se estima mediante:

Incidencia $=\frac{\text { Nùmero de casos nuevos de una enfermedad }}{\text { Total de población en riesgo }} \times \mathbf{1 0 0}$ 
"Como todas las proporciones, la incidencia no tiene dimensión y nunca toma valores menores de 0 a mayores de 1 , siendo frecuente expresarla en términos de porcentaje, en tanto por ciento, tanto por mil, en función de la "rareza" de la enfermedad estudiada". ${ }^{13}$

\section{La prevalencia (P)}

La prevalencia cuantifica la proporción de individuos de una población que padecen una enfermedad en un momento o periodo de tiempo determinado. ${ }^{10-11}$ Su cálculo se estima mediante:

Prevalencia $=\frac{\text { Número de casos con la enfermedad en un momento dado }}{\text { Total de población en ese momento }} \times \mathbf{1 0 0}$

“Como todas las proporciones, la prevalencia no tiene dimensión y nunca toma valores menores de 0 a mayores de 1 , siendo frecuente expresarla en términos de porcentaje, en tanto por ciento, tanto por mil, en función de la "rareza" de la enfermedad estudiada". ${ }^{13}$

\section{METODOLOGÍA}

El trabajo de investigación se realizó mediante un enfoque cuantitativo; la investigación cuantitativa es aquella en la que se acumulan y examinan datos cuantitativos sobre variables y estudia las propiedades y fenómenos cuantitativos. Según Hurtado y Toro (1998) citado por Díaz. ${ }^{14,15}$

\section{POBLACIÓN}

Esta investigación se centró en la población de contagiados, recuperados y personas fallecidas por COVID-19 en Colombia, con la información proveniente del Instituto Nacional de Salud ${ }^{16}$, la población para determinar los cálculos para el año 2020 según el DANE $^{17}$ fue 50'372.424, y para el año 2021 de 51'049.498 habitantes. Se utilizó el paquete estadístico SPSS v.25.

\section{RESULTA DOS}

En la figura 1 se aprecian las tendencias de personas contagiadas, recuperadas y fallecidas, durante el período 6 de marzo 2020 a 28 de febrero 2021, para los contagiados y recuperados la tendencia es exponencial, y para los fallecidos lineal.

En el mes de marzo 2020 se produjeron 906 casos de contagio, 31 personas recuperadas y 31 fallecimientos. En el mes de febrero 2021 se ocasionaron 2'251.690 casos de contagio, 2'148.249 personas recuperadas y 59.766 fallecimientos.

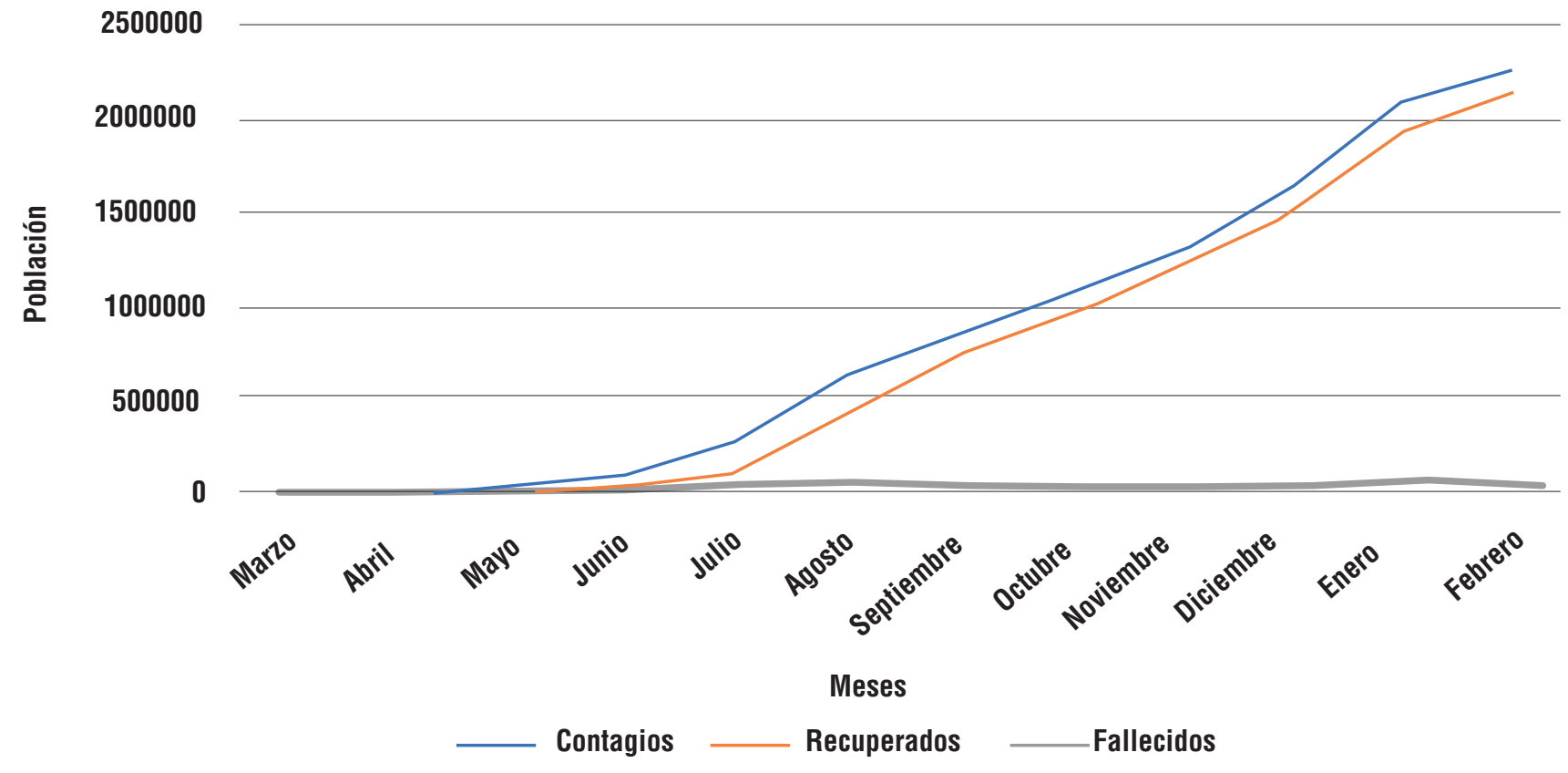

Fuente: el autor

Figura 1. Tendencia acumulada para contagiados, recuperados, y fallecidos por COVID-19. 


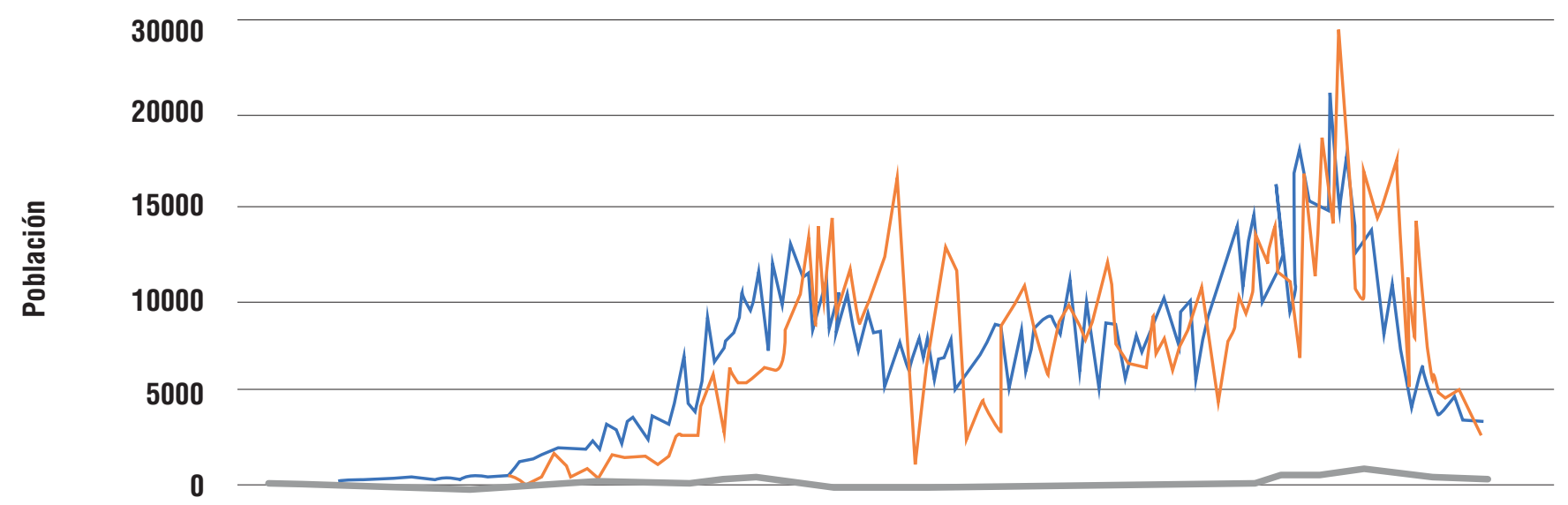

— 꿍 \&

Días

Fuente: el autor

Contagios

Recuperados

Fallecidos

Figura 2. Tendencia diaria para contagiados, recuperados, y fallecidos por COVID-19.

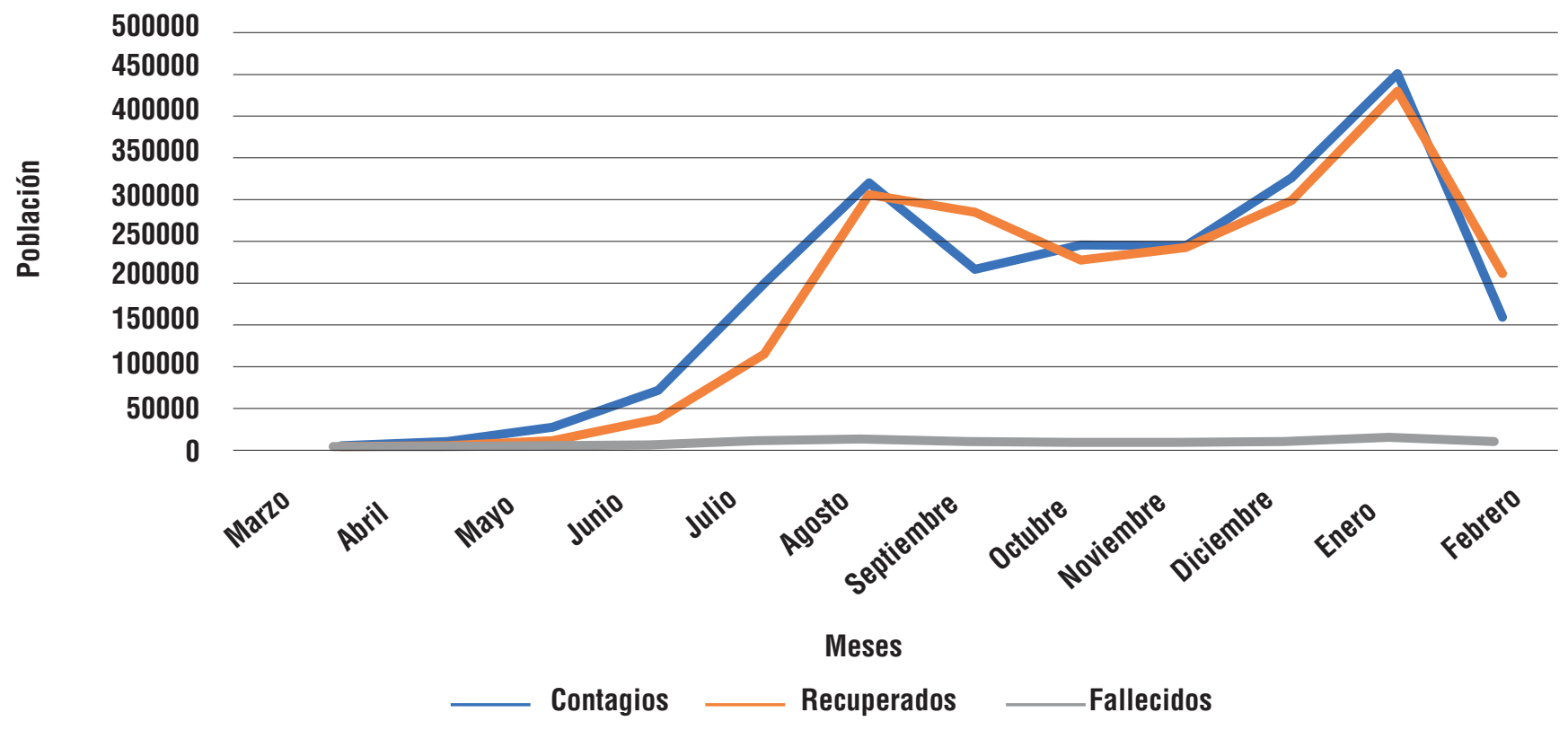

Fuente: el autor

Figura 3. Tendencia por meses para contagiados, recuperados, y fallecidos por COVID-19.

En la figura 2 se observan las tendencias de personas contagiadas, recuperadas y fallecidas a diario, se estableció que para el 18 de enero 2021 (día 319) se presentó el mayor pico de contagio con 24.589, para el día 18 de enero 2021 (día 319), se ubicó el pico mayor de personas recuperadas con 24.589 y para el día 22 de agosto 2020 (día 170) se apreció el mayor pico de fallecimientos con 400.

En la figura 3 se describen las tendencias de personas contagiadas, recuperadas y fallecidas por meses, se estableció que para el mes de agosto 2020 se presentó el primer pico de la enfermedad con 319.660 casos de contagio, en este mismo mes se ubicó un número de personas recuperadas con 305.088 y se apreció un total de fallecimientos con 305.088. En el mes de enero 2021 se apreció un segundo pico de la enfermedad más agresivo con 451.609 casos de contagio, personas recuperadas con 429.903 y un número de fallecidos de 10.770 . 
En la figura 4 se establecieron las tasas de letalidad por COVID-19 por meses en Colombia, se aprecia que el mes con mayor porcentaje de letalidad por cada 100 habitantes está en primer lugar abril 2020 con una tasa de 4,71\%, febrero 2021 con $3,68 \%$, junio 2020 con $3,49 \%$; seguimos con julio 2020 con 3,42\%, marzo 2020 con 3,2\%, agosto 2020 con $2,99 \%$, septiembre 2020 con 2,95\%, mayo 2020 con $2,82 \%$, enero 2021 con $2,38 \%$, noviembre 2020 con $2,25 \%$, octubre 2020 con $2,17 \%$ y el mes con menor porcentaje de letalidad se ubicó en diciembre 2020 con 1,97\%.

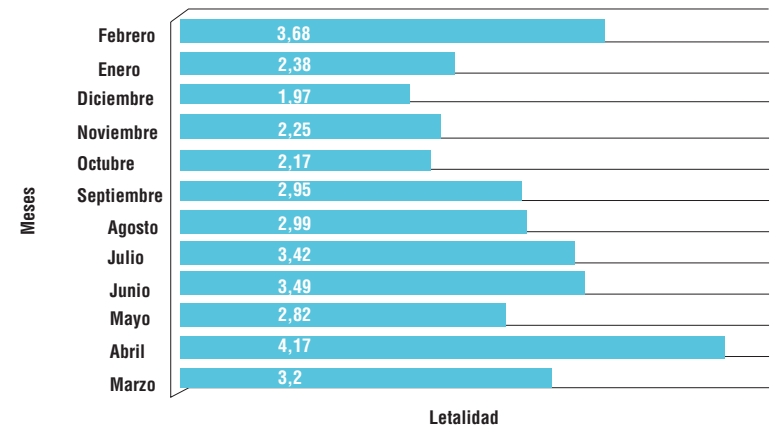

Fuente: el autor

Figura 4. Tasas de letalidad por COVID-19, por meses en Colombia al 28 de febrero 2021.

En la figura 5 se aprecian los datos de la incidencia en porcentaje $(\%)$, para cada uno de los meses de marzo a diciembre 2020 en Colombia, se detalla que los meses con mayor incidencia de casos positivos por COVID-19 para el año 2020 , están: diciembre $0,664 \%$, agosto $0,638 \%$, octubre $0,492 \%$ y septiembre $0,431 \%$; y en los meses con menor incidencia tenemos julio 0,393\%, junio 0,135\%, mayo 0,04\%, abril 0,011\% y marzo 0,001\%. Durante el año 2021, tenemos enero $0,884 \%$ y febrero $0,31 \%$.

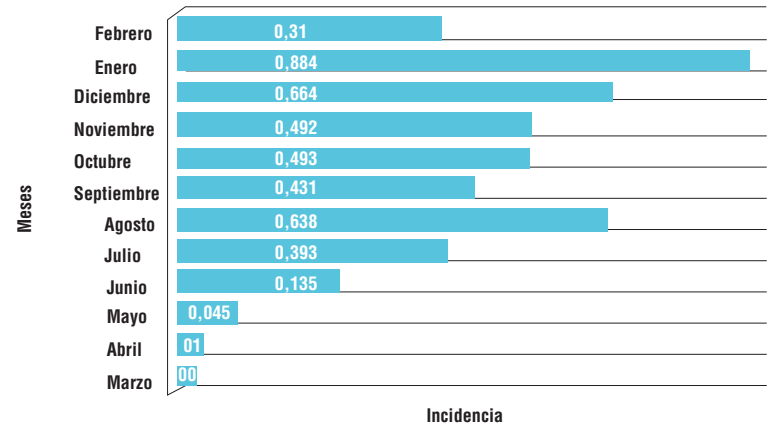

Fuente: el autor

Figura 5. Tasas de incidencia por COVID-19, por meses en Colombia al 28 de febrero 2021.

En la figura 6 se aprecian los datos de la prevalencia en porcentaje (\%) para cada uno de los meses de marzo a diciembre 2020 en Colombia, se detalla que los meses con mayor incidencia de casos positivos por COVID-19 para 2020, fueron: diciembre 3,26\%, noviembre 2,61\%, octubre $2,13 \%$ y septiembre $1,64 \%$; y en los meses con menor incidencia tuvimos agosto $1,22 \%$, julio $0,58 \%$, junio 0,19\%, mayo 0,05\%, abril 0,01\% y marzo 0,001\%. Durante el año 2021 , tenemos enero $4,1 \%$, y febrero $4,41 \%$.

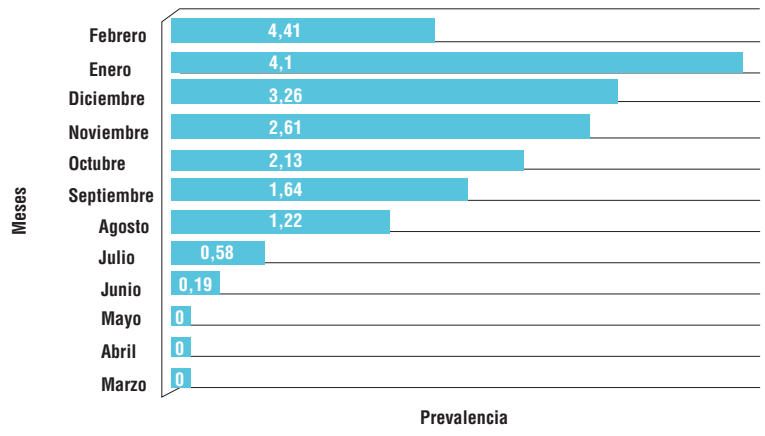

Fuente: el autor

Figura 6. Tasas de prevalencia por COVID-19, por meses en Colombia al 28 de febrero 2021.

\section{CONCLUSIONES}

Se determinaron las tendencias de personas contagiadas, recuperadas y fallecidas durante el período 6 de marzo 2020 a 28 de febrero 2021, para los contagiados y recuperados la tendencia es exponencial y para los fallecidos lineal. En el mes de marzo 2020 se produjeron 906 casos de contagio, 31 personas recuperadas y 31 fallecimientos. En el mes de febrero 2021 ocurrieron 2'251.690 casos de contagio, 2'148.249 personas recuperadas y 59.766 fallecimientos.

Se estableció que para el mes de agosto 2020 se presentó el primer pico de la enfermedad con 319.660 casos de contagio, en este mismo mes se ubicó un número de personas recuperadas con 305.088 y se apreció un total de fallecimientos con 305.088. En el mes de enero 2021 apareció un segundo pico de la enfermedad más agresivo con 451.609 casos de contagio, personas recuperadas con 429.903 y un número de fallecidos de 10.770. Se calcularon las tasas de letalidad por COVID-19 por meses en Colombia, observando que el mes con mayor porcentaje de letalidad por cada 100 habitantes está en primer lugar abril 2020 con una tasa de $4,71 \%$, y febrero 2021 con 3,68\%.Para el caso de la incidencia se determinó que el mes con mayor tasa de porcentaje se ubicó en el mes de enero 2021 con $0,884 \%$ y diciembre 2020 con $0,664 \%$. En la otra medida epidemiológica de la prevalencia, se fijó que los meses con mayor tasa de porcentaje se ubican en 2021: enero 4,1\%, y febrero $4,41 \%$.Es transcendental estudiar la dinámica de posibles brotes infecciosos del COVID-19 en nuestro país, ya que esta enfermedad recientemente surgida ha tenido un rápido crecimiento contagioso.18 Es así que en Colombia la curva de casos nuevos diarios ha contribuido para explicar la curva epidemiológica del país. 


\section{REFEREN CIAS}

1. BMJ. Enfermedad por coronavirus 2019 (COVID-19). [Internet]. 2020 [ Citado el 13 de enero de 2021]. Recuperado de: https:// bestpractice.bmj.com/topics/es-es/3000201

2. Zhou P, ZL. SARS-CoV-2 spillover events. Science. 2021 Jan 8;371(6525):120-122. doi: 10.1126/science.abf6097

3. Li Q, Guan X, Wu P, Wang X, Zhou L, Tong Y, Ren R, et al. Early Transmission Dynamics in Wuhan, China, of Novel CoronavirusInfected Pneumonia. N Engl J Med. 2020;382(13):1199-1207. doi: 10.1056/NEJMoa2001316

4. Zhou F, Yu T, Du R, Fan G, Liu Y, Liu, Z. Clinical course and risk factors for mortality of adult inpatients with COVID-19 in Wuhan China: a retrospective cohort study. Lancet. 2020;395(10229):10541062. doi: 10.1016/S0140-6736(20)30566-3

5. Guan WJ, Ni ZY, Hu Y, Liang WH, Ou CQ, He JX, et al. Clinical Characteristics of Coronavirus Disease 2019 in China. J Emerg Med 2020 Apr; 58(4): 711-712. doi: 10.1016/j.jemermed.2020.04.004

6. Fauci, AS, Lane HC, Redfield RR. Covid-19 - Navigating the Uncharted. N Engl J Med. 2020 Mar 26;382(13):1268-1269. doi: 10.1056/NEJMe2002387

7. Kucharski A, Klepac P, Conlan A, Kissler S, Tang M, Fry H, et al Effectiveness of isolation, testing, contact tracing and physical distancing on reducing transmission of SARS-CoV-2 in different settings. medRxiv. 2020;20(10):P1151-1160 doi: 10.1016/S14733099(20)30457-6

8. Cooke SJ, Cramp RL, Madliger CL, Bergman JN, Reeve C, Rummer JL, Hultine KR, et al. Conservation physiology and the COVID-19 pandemic. Conserv Physiol. 2021 Jan 12;9(1):coaa139. doi 10.1093/conphys/coaal39

9. Díaz-Pinzón JE. Uso de modelo predictivo para la dinámica de transmisión del COVID-19 en Colombia. Repert Med Cir. 2020;29(Núm. Supl.1):34-44. doi: 10.31260/ RepertMedCir.01217372.1056
10. Moreno-Altamirano A, López-Moreno S, Corcho-Berdugo A. Principales medidas en epidemiología. Revista Cubana de Higiene y Epidemiología. 2007;45(1):337-48.

11. Quintana-Salgado. L. Medidas de frecuencia en epidemiología [Internet]. 2015 Slideshare; [Citado 25 de julio de 2020]. Disponible en: https://es.slideshare.net/lualberts20/medidas-de-frecuenciaen-epidemiologa-2015

12. Pinto, A. Prevalencia e Incidencia [Internet]. Slideshare; 2014. [Citado 21 de julio de 2020]. Disponible en: https://es.slideshare.net/alexpintol8/ prevalencia-e-incidencia-2?next_slideshow $=2$

13. Fisterra. Medidas de frecuencia de enfermedad [Internet]. 2004. [Citado 21 de agosto de 2020]. Disponible en: https://www.fisterra.com/ formacion/metodologia-investigacion/medidas-frecuencia-enfermedad/

14. Díaz-Pinzón, J.E. Correlación y regresión lineal de la evaluación tiempo y puntaje con recurso interactivo flash. INNOVA Research Journal. 2017;2(10):1-8. doi: 10.33890/innova. v2.n10.2017

15. Díaz-Pinzón JE. Estudio de los resultados del contagio por COVID-19 a nivel mundial. Repert Med Cir. 2020;29(Núm. Supl.1):65-71. doi: 10.31260/RepertMedCir.01217372.1089

16. Instituto Nacional de Salud. Coronavirus (COVID-2019) en Colombia [Internet]. Bogotá: Instituto Nacional de Salud; 2020. [citado 2021 febrero 28]; Recuperado de: https://www.ins.gov.co/ Noticias/Paginas/Coronavirus.aspx

17. Departamento Administrativo Nacional de Estadística. DANE. Proyecciones y retroproyecciones de población [Internet]. 2000. [Citado 28 de febrero de 2021]. Disponible en: https://www.dane. gov.co/index.php/estadisticas-por-tema/demografia-y-poblacion/ proyecciones-de-poblacion

18. Díaz Pinzón JE. Estudio comparativo entre el contagio durante la cuarentena obligada por el COVID-19 y el contagio durante la apertura gradual y controlada para algunos sectores de la economía en Colombia. Repert Med Cir. 2020;29(Supl.Núm.1):5964. doi: 10.31260/RepertMedCir.01217372.1073 